\title{
(6) OPEN ACCESS \\ Influence of past breast feeding on pattern and severity of presentation of juvenile idiopathic arthritis
}

\author{
Kimme L Hyrich, ${ }^{1,2}$ Eileen Baildam, ${ }^{3}$ Hannah Pickford, ${ }^{1}$ Alice Chieng, ${ }^{4}$ \\ Joyce E Davidson, ${ }_{1}^{5}$ Helen Foster, ${ }^{6}$ Janet Gardner-Medwin, ${ }^{7}$ Lucy R Wedderburn, ${ }^{8,9,10}$ \\ Wendy Thomson ${ }^{1,2}$
}

For numbered affiliations see end of article.

\section{Correspondence to} Dr Kimme Hyrich, Arthritis Research UK Centre for Epidemiology, Centre for Musculoskeletal Research, Institute of Inflammation and Repair, The University of Manchester, Manchester Academic Health Science Centre, Room 2.800 Stopford Building, Oxford Road, Manchester M13 9PT, UK; kimme.hyrich@manchester. ac.uk

Received 22 December 2014 Revised 23 June 2015 Accepted 24 June 2015 Published Online First 14 September 2015

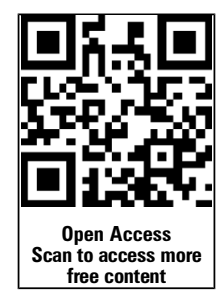

CrossMark

To cite: Hyrich $\mathrm{KL}$,

Baildam $\mathrm{E}$, Pickford $\mathrm{H}$, et al. Arch Dis Child

2016;101:348-351.

\section{ABSTRACT}

This analysis aimed to study the influence of breast feeding on the pattern and severity of juvenile idiopathic arthritis ( JIA) at presentation. The association between ever versus never breast feeding and disease severity at onset was compared in 923 children with JIA recruited to the UK Childhood Arthritis Prospective Study at first presentation to rheumatology. Fifty six per cent of children were ever breast fed (median 3.7 months). Breastfed children reported a lower median age at onset, a lower Childhood Health Assessment Questionnaire (CHAQ), a measure of disease severity, lower parent general evaluation scores and lower pain at presentation. There was a trend towards a higher proportion of breastfed children with rheumatoid factor-negative polyarthritis, but lesser enthesitis-related and psoriatic arthritis. There was a statistically significant inverse association between breast feeding and high CHAQ, even after adjusting for differences in socioeconomic status (adjusted OR 0.61 (95\% Cl 0.39 to 0.95$)$ ). Further work to understand the reasons behind these associations is required.

\section{INTRODUCTION}

Juvenile idiopathic arthritis (JIA) is a heterogeneous chronic inflammatory arthritis, classified by the International League Against Rheumatism (ILAR) into seven categories. The aetiology remains unknown.

There is interest in the association between breast feeding, immune system development and future development of autoimmune diseases. Breast milk is a rich source of immunological defences, which help to stimulate the infant's immature immune system, and may have an important role in the establishment of gut flora and defence against infection.

The potential relationship between breast feeding and susceptibility to JIA has been described in small case-control studies, ${ }^{1-4}$ although only one study has suggested an association between breast feeding and decreased susceptibility. Two studies found shorter $^{3}$ or less frequent ${ }^{1}$ breast feeding among children who developed oligoarticular disease compared with controls, which was not confirmed in a third study. ${ }^{2}$ No study has looked at the severity or timing of JIA presentation. Our aim was to study the influence of exposure to, and duration of, breast feeding on pattern and severity of JIA at first presentation to rheumatology.

\section{What is already known on this topic}

The aetiology of juvenile idiopathic arthritis remains poorly understood.

- Research into environmental and genetic risk factors has been conflicting.

- Breast feeding may be associated with lesser occurrence or delayed onset of autoimmune diseases.

\section{What this study adds}

Patterns of arthritis may differ between children ever versus never breast fed.

- Breast feeding may be associated with a milder onset of juvenile idiopathic arthritis.

\section{METHODS}

This study included children in the Childhood Arthritis Prospective Study (CAPS) using methods, which have been detailed elsewhere. ${ }^{5}$ In brief, at presentation to paediatric rheumatology and at regular follow-up, demographic and clinical data are collected from the medical record, and families attend an interview to detail birth and health history, including whether the child was breast fed and for how long. CAPS was approved by the UK Research Ethics Committee, and written consent was obtained from all participants.

Baseline demographic and clinical characteristics were compared between children ever versus never breast fed using non-parametric descriptive statistics. Socioeconomic status (SES) was based on the patient's postcode, and classified using the 2007 Index of Multiple Deprivation (IMD), an England-specific location-based deprivation score, which takes into consideration a number of social indicators. Children were grouped into three national ranked categories. IMD scores are not comparable across the four countries in the UK, and therefore, SES data are only presented for children resident in England (80\% of cohort). Characteristics were also analysed according to the duration of breast feeding using univariable logistic and linear regression models. An association between ever breast feeding and moderate-to-severe 
disease at presentation, defined using a Child Health Assessment Questionnaire (CHAQ) score $>0.75^{6}$, was explored using a multivariable logistic regression model, adjusted for a priori selected covariates (onset age, gender, hospital, disease duration, ILAR category and IMD) as well as any variables significant in univariable analysis. Multiple imputation (25 iterations) was used to account for missing data.

\section{RESULTS}

To 05/2012, 1253 children had been recruited; 1015 (81\%) attended for interview, and 923 (74\%) answered the breastfeeding questions. Those without breastfeeding data were older (median 8.6 vs 6.4 years, $\mathrm{p}<0.001$ ) with lower disease activity (median Physician Global Assessment (PGA) score 24/ 100 vs 29/100, $\mathrm{p}=0.01$ ), but were otherwise similar.

Five hundred and thirteen (56\%) children were reported to have ever breast fed; median duration 3.7 months, $14 \%$ $\geq 6$ months, $5 \% \geq 1$ year.

There were many demographic and clinical differences between children ever versus never breast fed (table 1), including presentation at a younger age and lower deprivation scores. In general, disease activity and severity were also lower among

Table 1 Demographic factors and disease characteristics at presentation in children with JIA ever versus never breast fed

\begin{tabular}{|c|c|c|c|c|c|}
\hline Characteristic & Total cohort & $\begin{array}{l}\text { Never breast } \\
\text { fed }\end{array}$ & Ever breast fed & $\begin{array}{l}p \text { Value (ever vs } \\
\text { never breast fed) }\end{array}$ & $\begin{array}{l}\text { Univariate analysis of } \\
\text { association between covariate } \\
\text { and } \mathrm{CHAQ}>0.75(\mathrm{OR}, 95 \% \mathrm{Cl})\end{array}$ \\
\hline $\mathrm{N}(\%)$ & 923 & 410 (44) & $513(56)$ & & \\
\hline Female, $n(\%)^{*}$ & $604(65)$ & $262(64)$ & $342(67)$ & 0.4 & $0.87(0.61 \text { to } 1.23)^{*}$ \\
\hline Caucasian, $\mathrm{n}(\%)^{*}$ & $831(90)$ & 381 (93) & $450(88)$ & 0.009 & $1.08(0.65 \text { to } 1.80)^{*}$ \\
\hline \multicolumn{6}{|l|}{$\begin{array}{l}\text { Index of Multiple Deprivation category }(n=737), n \\
(\%)^{*}, \dagger\end{array}$} \\
\hline Low & $143(20)$ & $37(11)$ & $106(26)$ & $<0.001$ & Ref \\
\hline Medium & $334(45)$ & $139(43)$ & $195(47)$ & & 1.33 (0.86 to 2.06$)$ \\
\hline High & $260(35)$ & $149(46)$ & $111(27)$ & & 1.76 (1.13 to 2.74$)$ \\
\hline \multicolumn{6}{|l|}{ Referral hospital, n (\%)* } \\
\hline Liverpool & $383(42)$ & $183(45)$ & $200(39)$ & $<0.001$ & Ref \\
\hline Manchester & $174(19)$ & $83(20)$ & $91(18)$ & & 0.91 (0.60 to 1.38$)$ \\
\hline Glasgow & 139 (15) & $68(16)$ & $71(14)$ & & - \\
\hline Newcastle & $50(5)$ & $28(7)$ & $22(4)$ & & $0.87(0.45$ to 1.68$)$ \\
\hline London & 177 (19) & $48(12)$ & $129(25)$ & & 1.07 (0.71 to 1.62$)$ \\
\hline Age at symptom onset (years), median (IQR)* & $6.4(2.5,11)$ & $7.6(3.2,11)$ & $5.7(2.0,10)$ & $<0.001$ & 0.97 (0.93 to 1.01$)$ \\
\hline $\begin{array}{l}\text { Symptom duration at first visit (months), median } \\
(\mathrm{IQR})^{*}\end{array}$ & $5.6(2.9,12)$ & $5.6(2.8,13)$ & $5.6(2.9,11)$ & 0.6 & 1.00 (0.99 to 1.01$)$ \\
\hline Active joint count, median (IQR) & $2(1,5)$ & $2(1,5)$ & $2(1,5)$ & 0.6 & - \\
\hline 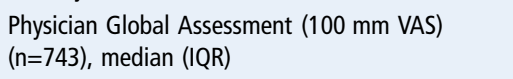 & $29(16,53)$ & $32(18,56)$ & $28(15,50)$ & 0.03 & - \\
\hline ESR $(n=570)$, median (IQR) & $20(6,50)$ & $18(6,47)$ & $22(7,53)$ & 0.1 & - \\
\hline $\begin{array}{l}\text { Parent global assessment (100 mm VAS) }(n=656) \text {, } \\
\text { median (IQR) }\end{array}$ & $21(5,50)$ & $39(10,64)$ & $23(5,50)$ & $<0.001$ & - \\
\hline JADAS-71, $\neq$ median (IQR), $(n=340)^{*}$ & $11(6-18)$ & $13(7-20)$ & $10(6-17)$ & 0.02 & 1.10 (1.07 to 1.12$)$ \\
\hline Limited joint count, median (IQR)* & $1(1,3)$ & $1(1,3)$ & $1(1,3)$ & 0.3 & 1.09 (1.04 to 1.14$)$ \\
\hline Pain (100 mm VAS) ( $n=664)$, median (IQR)* & $30(8,58)$ & $29(7,54)$ & $18(4,45)$ & $<0.001$ & $1.04(1.03$ to 1.05$)$ \\
\hline CHAQ score ( $n=674)$, median (IQR) & $0.63(0.13,1.38)$ & $0.88(0.25,1.63)$ & $0.63(0.13,1.25)$ & $<0.001$ & \\
\hline$\%$ CHAQ $>0.75(n=674), n(\%)$ & $303(45)$ & $159(54)$ & $144(38)$ & $<0.001$ & \\
\hline \multicolumn{6}{|l|}{ ILAR subtype, n (\%)* } \\
\hline Systemic & $49(5)$ & $23(6)$ & $26(5)$ & 0.05 & Ref \\
\hline Oligoarthritis (persistent) & $427(46)$ & $189(46)$ & $238(46)$ & & $0.56(0.27$ to 1.17$)$ \\
\hline Oligoarthritis (extended) & $59(7)$ & $28(7)$ & $31(6)$ & & $1.19(0.43$ to 3.31$)$ \\
\hline Polyarthritis (RF-) & $215(23)$ & 79 (19) & $136(27)$ & & 1.69 (0.73 to 3.79$)$ \\
\hline Polyarthritis $(\mathrm{RF}+)$ & $27(3)$ & $11(3)$ & $16(3)$ & & $2.36(0.59$ to 9.46$)$ \\
\hline Enthesitis related & $52(6)$ & $32(8)$ & $20(4)$ & & $0.78(0.29$ to 2.10$)$ \\
\hline Psoriatic & $67(7)$ & $36(8)$ & $31(6)$ & & $0.62(0.24$ to 1.57$)$ \\
\hline Undifferentiated & $27(3)$ & $12(3)$ & $15(3)$ & & $0.47(0.14$ to 1.60$)$ \\
\hline $\begin{array}{l}\text { OR }(95 \% \mathrm{Cl}) \mathrm{CHAQ}>0.75 \text { in ever versus never } \\
\text { breast fed (univariable) } \S \mathrm{n}=737\end{array}$ & & & & & $0.68(0.48$ to 0.95$)$ \\
\hline $\begin{array}{l}\text { OR }(95 \% \mathrm{Cl}) \mathrm{CHAQ}>0.75 \text { in ever versus never } \\
\text { breast fed (adjusted) } \uparrow \mathrm{n}=737\end{array}$ & & & & & 0.61 (0.39 to 0.95$)$ \\
\hline
\end{tabular}

*Indicates variables included in multivariable logistic regression analysis.

tIndicates the number of children with the available measure when not present in all children

ҒJADAS-71: composite score of 71 active joint count, Physician Global Assessment, parent general evaluation and ESR.

§AUC 0.55 .

IAUC 0.84.

AUC, area under the curve; CHAQ, Childhood Health Assessment Questionnaire; ESR, erythrocyte sedimentation rate; ILAR, International League Against Rheumatism; JADAS, Juvenile Arthritis Disease Activity Score; JIA, juvenile idiopathic arthritis; Ref, reference; RF, rheumatoid factor; VAS, visual analogue scale. 
Table 2 Demographic and clinical characteristics according to length of breast feeding*

\begin{tabular}{|c|c|c|c|c|c|}
\hline Characteristict & Never & $<3$ months & $\geq 3$ and $<6$ months & $\geq 6$ months & $p$ Value for trend \\
\hline $\mathrm{N}(\%)$ & $410(46)$ & $233(26)$ & $124(14)$ & $131(15)$ & \\
\hline Female, $\mathrm{n}(\%)$ & $262(64)$ & $154(66)$ & $85(69)$ & $90(69)$ & 0.2 \\
\hline Caucasian, n (\%) & $381(93)$ & $208(89)$ & $113(91)$ & $111(85)$ & 0.01 \\
\hline \multicolumn{6}{|l|}{ Index of Multiple Deprivation ( $n=737), n(\%)$} \\
\hline Low & $37(11)$ & $44(23)$ & $26(27)$ & $34(32)$ & $<0.001$ \\
\hline Medium & $139(43)$ & $93(48)$ & $45(48)$ & $47(45)$ & \\
\hline High & $149(46)$ & $57(29)$ & $25(25)$ & $24(23)$ & \\
\hline Age at symptom onset (years), median (IQR) & $7.5(3.4,11.5)$ & $6.0(2.5,10.4)$ & $5.0(1.9, .9 .7)$ & $4.8(2,9.9)$ & 0.002 \\
\hline Symptom duration (months), median (IQR) & $5.6(2.8,12.5)$ & $5.5(2.9,10.3)$ & $5.3(2.9, .14 .3)$ & $5.3(2.9,14.3)$ & 0.5 \\
\hline Active joint count, median (IQR) & $2(1,5)$ & $2(1, .6)$ & $2(1,4)$ & $2(1,6)$ & 0.4 \\
\hline Limited joint count, median (IQR) & $1(1,3)$ & $1(1,3)$ & $1(0,3)$ & $1(1,3)$ & 0.08 \\
\hline Physician global assessment ( $n=743)$, median (IQR) & $32(18,56)$ & $30(18,57)$ & $25(12,46)$ & $24(13,49)$ & 0.005 \\
\hline ESR $(n=570)$, median (IQR) & $18(6,47)$ & $20(6,50)$ & $29(7,55)$ & $21(9,53)$ & 0.1 \\
\hline CHAQ score $(n=674)$, median (IQR) & $0.88(0.25,1.63)$ & $0.63(0.13,1.25)$ & $0.63(0.13,1.25)$ & $0.5(0,1.13)$ & $<0.001$ \\
\hline CHAQ >0.75 ( $n=674), n(\%)$ & $136(46)$ & $63(39)$ & $35(41)$ & $39(37)$ & 0.001 \\
\hline Parent general evaluation. (100 mm VAS) ( $n=656)$, median (IQR) & $39(10,64)$ & $16(3,45)$ & $27(4,50)$ & $17(5,42)$ & 0.008 \\
\hline Pain (100 mm VAS) ( $n=664)$, median (IQR) & $29(7,54)$ & $22(4,53)$ & $28(5,60)$ & $20(6,45)$ & 0.005 \\
\hline JADAS-71, median (IQR) & $13.2(7-19.9)$ & $10.4(5.9-16.9)$ & $10.2(5-21.3)$ & $10.6(4.5-15.6)$ & 0.1 \\
\hline \multicolumn{6}{|l|}{ ILAR Subtype, n (\%) } \\
\hline Systemic arthritis & $23(6)$ & $8(4)$ & $9(7)$ & $7(5)$ & 0.09 \\
\hline Oligoarthritis (persistent) & $189(46)$ & $101(43)$ & $64(51)$ & $59(45)$ & \\
\hline Oligoarthritis (extended) & $28(7)$ & $13(6)$ & $10(8)$ & $6(4)$ & \\
\hline Polyarthritis (RF negative) & $79(19)$ & $73(31)$ & $22(18)$ & $38(29)$ & \\
\hline Polyarthritis (RF positive) & $11(3)$ & $8(3)$ & $5(4)$ & $2(2)$ & \\
\hline Enthesitis-related arthritis & $32(8)$ & $11(5)$ & $4(3)$ & $4(3)$ & \\
\hline Psoriatic arthritis & $36(9)$ & $12(5)$ & $8(7)$ & $10(8)$ & \\
\hline Undifferentiated arthritis & $12(3)$ & $7(3)$ & $2(2)$ & $5(4)$ & \\
\hline
\end{tabular}

* Duration of breast feeding not reported for 25 children.

tNumbers in brackets in first column indicate available data where data items were missing or not available.

CHAQ, Childhood Health Assessment Questionnaire; ILAR, International League Against Rheumatism; JADAS, Juvenile Arthritis Disease Activity Scores; RF, rheumatoid factor.

those ever breast fed, with lower PGA and Juvenile Arthritis Disease Activity Scores (JADAS). Patient-reported outcomes (CHAQ including the proportion of children with CHAQ $>0.75$ ), pain and Parent General Evaluation (PGE) scores were all significantly lower in children ever breast fed. There was also a small difference noted across the distribution of ILAR categories with a higher proportion of polyarthritis and a lower proportion of enthesitis-related arthritis (ERA) and psoriatic arthritis (PsA) among those ever versus never breast fed. The proportion of children presenting with an oligoarticular pattern was identical in both groups. Dose-response relationships were also observed in the age of onset, ethnicity, IMD, PGA and the CHAQ score (table 2), but less evident in other measures.

The relationship between ever breast fed and CHAQ score was explored in 737 children resident in England. After adjustment, ever breast feeding was associated with a 39\% lesser probability of presenting with a CHAQ $>0.75$ (OR 0.61 (95\% CI 0.39 to 0.95$)$ ) (table 1 ).

\section{DISCUSSION}

This study represents the first JIA study to investigate the impact of breast feeding on presentation of disease, and found breast feeding was associated with an earlier but milder presentation, the latter of which persisted after adjusting for marked SES differences.

The observation of a younger age of onset is interesting and different from research focusing on coeliac disease, which suggests breast feeding may delay the onset of childhood coeliac disease, ${ }^{7}$ although this relationship is confounded by timing of gluten introduction. It has been suggested that breast milk may stimulate the immature immune system, thus, triggering the autoimmune process of JIA in the right setting. ${ }^{8}$ Earlier onset could also be explained by differences in ILAR categories observed between the two groups, with a higher proportion of PsA/ERA in the never-breastfed group, which tend to present at a later age.

Previous reports on breast feeding and JIA have largely excluded children with ERA/PsA. Why breast feeding might alter/change susceptibility to certain subtypes of JIA is not clear, although there have been reports of differences in the microbiome between children with ERA and those without. ${ }^{9}$ Breast feeding may have a protective effect on early intestinal infections, and contribute to constitution of the gut flora, but further research is required to validate these findings.

Children who were ever breast fed reported lower CHAQ, pain and PGE, which also followed a dose-response relationship. This could relate to differences observed among SES between the groups, which have been shown to associate with reporting of the severity of disease. ${ }^{10}$ However, the relationship between CHAQ and breast feeding persisted after adjustment for SES. T cells contribute an important role to the pathogenesis of JIA, and breast milk is hypothesised to have a T-cell specific suppressant effect, which may in turn, reduce severity of presentation.

Breastfeeding rates in our study were low (56\%), but are in keeping with UK data, which highlights low UK rates compared with other European countries. It is possible that some misclassification of breastfeeding status is present as parents may 
have different views regarding when breast feeding becomes significant enough to answer the question 'was your child ever breastfed?' with 'yes'. The fact that we have identified a link between breast feeding and presentation of JIA despite potential misclassification further strengthens our findings.

This study is not without limitations. We tried to capture SES using national deprivation scores, but these only refer to the area of residence and not the individuals themselves. They also represent the current SES and not necessarily that at the time of the child's birth. Unfortunately, data on maternal age and education were not available, but we did include referral hospital as a further geographical marker, which may influence the decision to breast feed. Data on exclusivity of breast feeding was not captured. Finally, and most importantly, as we did not have access to a control group, the data cannot be used to comment on susceptibility to JIA, including susceptibility to any individual ILAR subtype.

We recognise that these observations may have considerable impact on prospective parents, and therefore, it is important that these findings are explored further to consider how breast feeding might influence the presentation of JIA. Further research should also focus on whether breast feeding may influence the susceptibility to JIA and in particular, its different patterns.

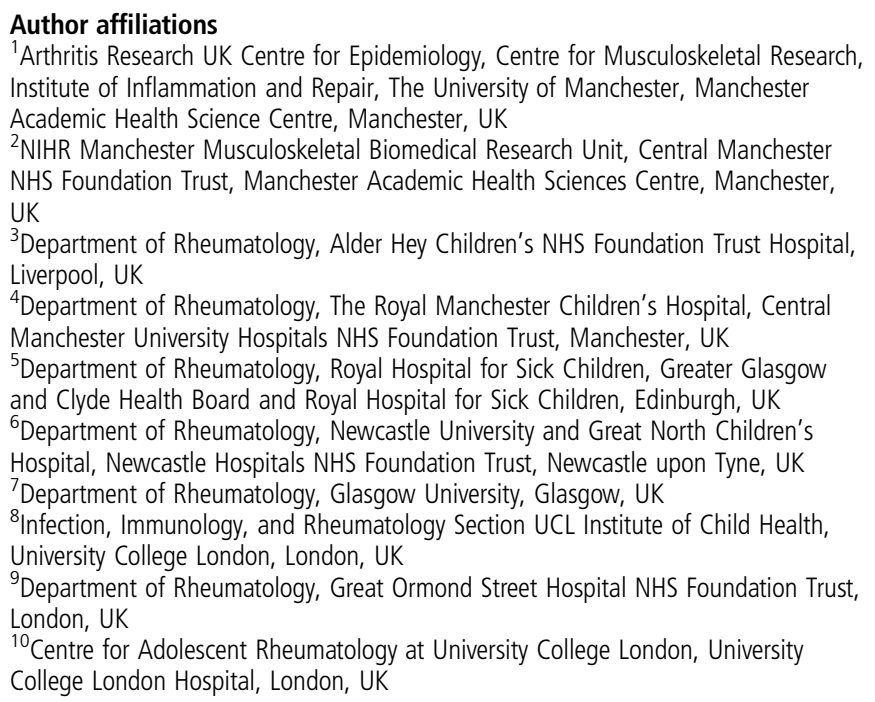

${ }^{1}$ Arthritis Research UK Centre for Epidemiology, Centre for Musculoskeletal Research, Institute of Inflammation and Repair, The University of Manchester, Manchester Academic Health Science Centre, Manchester, UK

${ }^{2} \mathrm{NIHR}$ Manchester Musculoskeletal Biomedical Research Unit, Central Manchester NHS Foundation Trust, Manchester Academic Health Sciences Centre, Manchester, UK

${ }^{3}$ Department of Rheumatology, Alder Hey Children's NHS Foundation Trust Hospital, Liverpool, UK

${ }^{4}$ Department of Rheumatology, The Royal Manchester Children's Hospital, Central Manchester University Hospitals NHS Foundation Trust, Manchester, UK

${ }^{5}$ Department of Rheumatology, Royal Hospital for Sick Children, Greater Glasgow and Clyde Health Board and Royal Hospital for Sick Children, Edinburgh, UK ${ }^{6}$ Department of Rheumatology, Newcastle University and Great North Children's Hospital, Newcastle Hospitals NHS Foundation Trust, Newcastle upon Tyne, UK ${ }^{7}$ Department of Rheumatology, Glasgow University, Glasgow, UK

${ }^{8}$ Infection, Immunology, and Rheumatology Section UCL Institute of Child Health, University College London, London, UK

${ }^{9}$ Department of Rheumatology, Great Ormond Street Hospital NHS Foundation Trust, London, UK

${ }^{10}$ Centre for Adolescent Rheumatology at University College London, University College London Hospital, London, UK

Acknowledgements The authors would like to thank the CAPS centres and staff as well as the children and families who have contributed to this study. This report includes independent research supported by the National Institute for Health Research Biomedical Research Unit Funding Scheme.

Contributors KLH, HP, EB and WT were responsible for data cleaning and data analysis. EB, AC, JED, HE, JG-M and LRW were responsible for data collection and contribution to the final analysis.

Funding Arthritis Research UK (grant code 20542).

Competing interests None declared.

Ethics approval UK Multicentre Research Ethics Committee.

Provenance and peer review Not commissioned; externally peer reviewed.

Data sharing statement Data held within CAPS is open to third-party sharing. Applications for CAPS data are received and reviewed by the Scientific Steering Committee. Further information is available at http://www.inflammation-repair. manchester.ac.uk/Musculoskeletal/research/CfE/caps/

Open Access This is an Open Access article distributed in accordance with the terms of the Creative Commons Attribution (CC BY 4.0) license, which permits others to distribute, remix, adapt and build upon this work, for commercial use, provided the original work is properly cited. See: http://creativecommons.org/ licenses/by/4.0/

\section{REFERENCES}

1 Mason T, Rabinovich CE, Fredrickson DD, et al. Breast feeding and the development of juvenile rheumatoid arthritis. I Rheumatol 1995;22:1166-70.

2 Rosenberg AM. Evaluation of associations between breast feeding and subsequent development of juvenile rheumatoid arthritis. J Rheumatol 1996;23:1080-2.

3 Kasapcopur 0, Tasdan Y, Apelyan M, et al. Does breast feeding prevent the development of juvenile rheumatoid arthritis? J Rheumatol 1998:25:2286-7.

4 Ellis JA, Ponsonby AL, Pezic A, et al. CLARITY_Childhood Arthritis Risk Factor Study. Pediatr Rheumatol Online J 2012;10:37.

5 Hyrich $\mathrm{KL}$, Lal SD, Foster $\mathrm{HE}$, et al. Disease activity and disability in children with juvenile idiopathic arthritis one year following presentation to paediatric rheumatology. Results from the Childhood Arthritis Prospective Study. Rheumatology (Oxford) 2010;49:116-22.

6 Spiegel LR, Schneider R, Lang BA, et al. Early predictors of poor functional outcome in systemic-onset juvenile rheumatoid arthritis: a multicenter cohort study. Arthritis Rheum 2000;43:2402-9.

7 Akobeng AK, Ramanan AV, Buchan I, et al. Effect of breast feeding on risk of coeliac disease: a systematic review and meta-analysis of observational studies. Arch Dis Child 2006;91:39-43.

8 Schack-Nielsen L, Michaelsen KF. Advances in our understanding of the biology of human milk and its effects on the offspring. J Nutr 2007;137:503S-10S.

9 Stoll ML, Kumar R, Morrow CD, et al. Altered microbiota associated with abnormal humoral immune responses to commensal organisms in enthesitis-related arthritis. Arthritis Res Ther 2014;16:486.

10 Verstappen SM, Cobb J, Foster HE, et al. Low socio-economic status is associated with high physical limitations and low illness self-perception in patients with juvenile idiopathic arthritis: results from the childhood arthritis prospective study (CAPS). Arthritis Care Res (Hoboken) 2015;67:382-9. 